\title{
Sleep Deprivation Alters Rat Ventral Prostate Morphology, Leading to Glandular Atrophy: A Microscopic Study Contrasted with the Hormonal Assays
}

\author{
Daniel P. Venâncio, ${ }^{1}$ Monica L. Andersen, ${ }^{2}$ Patricia S. L. Vilamaior, ${ }^{3}$ Fernanda C. Santos, ${ }^{4}$ \\ Adriano Zager, ${ }^{2}$ Sérgio Tufik, ${ }^{2}$ Sebastião R. Taboga, ${ }^{3}$ and Marco T. De Mello ${ }^{2}$ \\ ${ }^{1}$ Departamento de Nutrição, Universidade Federal de São Paulo (UNIFESP-EPM), Rua Marselhesa, 630, Vila Clementino, \\ 04020-620 São Paulo, SP, Brazil \\ ${ }^{2}$ Departamento de Psicobiologia, Universidade Federal de São Paulo (UNIFESP-EPM), Rua Napoleão de Barros, 295, \\ Vila Clementino, 04024-002 São Paulo, SP, Brazil \\ ${ }^{3}$ Departmento de Biología, Instituto de Biociências, Letras e Ciências Exatas (IBILCE), Universidade Estadual Paulista (UNESP), \\ Rua Cristóvão Colombo 2265, Jardim Nazareth, 15054-000 São José do Rio Preto, SP, Brazil \\ ${ }^{4}$ Departamento de Morfologia, Universidade Federal de Goiás, Campus II Samambaia, Caixa Posta 131, 74001-970 Goiânia, \\ GO, Brazil
}

Correspondence should be addressed to Sebastião R. Taboga, taboga@ibilce.unesp.br

Received 30 December 2011; Accepted 16 June 2012

Academic Editor: Oreste Gualillo

Copyright (๑) 2012 Daniel P. Venâncio et al. This is an open access article distributed under the Creative Commons Attribution License, which permits unrestricted use, distribution, and reproduction in any medium, provided the original work is properly cited.

We investigated the effect of $96 \mathrm{~h}$ paradoxical sleep deprivation (PSD) and 21-day sleep restriction (SR) on prostate morphology using stereological assays in male rats. After euthanasia, the rat ventral prostate was removed, weighed, and prepared for conventional light microscopy. Microscopic analysis of the prostate reveals that morphology of this gland was altered after $96 \mathrm{~h}$ of PSD and 21 days of SR, with the most important alterations occurring in the epithelium and stroma in the course of both procedures compared with the control group. Both $96 \mathrm{~h}$ PSD and 21-day SR rats showed lower serum testosterone and higher corticosterone levels than control rats. The significance of our result referring to the sleep deprivation was responsible for deep morphological alterations in ventral prostate tissue, like to castration microscopic modifications. This result is due to the marked alterations in hormonal status caused by PSD and SR.

\section{Introduction}

Sleep deprivation (SD) is a frequent condition in modern life due to the demands of our lifestyles [1], and sleep loss may trigger several alterations in organisms, including immunological effects [2-5], memory deficits [6-8], and hormonal abnormalities [9-14]. Shift work, obstructive sleep apnea, and other sleep disturbances may cause metabolic syndrome, which is strongly associated with male sex hormone alterations [15]. For instance, men affected by SD showed accentuated reduction of testosterone levels or hypogonadism [16]. Additionally, obstructive sleep apnea syndrome is frequently associated with decreased testosterone concentrations [17], fatigue, and erectile dysfunction [18, 19].
Our laboratory group has consistently demonstrated the effects of paradoxical sleep deprivation (PSD) on overall hormonal profiles in male rats; specifically we have found lower testosterone and estrone levels, but higher levels of progesterone, prolactin, corticosterone, and adrenocorticotropic hormone $(\mathrm{ACTH})[11,12]$. Interestingly, in contrast to humans, these rats showed increased genital reflexes, reflected in penile erections and ejaculatory frequency [9$12,20,21]$. In the male rat's reproductive system, 4-day PSD decreased the weight of the seminal vesicle and ventral prostate, indicating reduced steroidogenesis or diminished expression of androgens in target glands [22]. Indeed, PSD is inherently a stress condition, and other stress modalities 
that have been examined, such as immobilization, also lead to lower testosterone concentrations $[9,10]$. This can impair gonadal function by altering testicular maturation and the production of maturing sperm [23]. Moreover, it has been demonstrated that after castration, blood androgen levels as well as blood flow in the prostate (which is controlled by androgen levels) decrease abruptly. This reduction induces apoptosis in both endothelial and secretory epithelial cells [24]. However, the specific effects of PSD on prostate morphology have not been determined. Therefore, our objective was to examine the effect of PSD (96h) and chronic sleep restriction (21 days) on hormonal profiles and prostate histological patterns.

\section{Material and Methods}

2.1. Animals. Wistar male rats, aged 3 months and weighing 300-350 $\mathrm{g}$ at the beginning of the experiment, were obtained from the Instituto Nacional de Farmacologia (INFAR) colony at UNIFESP. The rats were housed inside standard polypropylene cages in a temperature-controlled $\left(23 \pm 1^{\circ} \mathrm{C}\right)$ room with a 12:12 h light-dark cycle (lights on at 06:00 hours). All procedures used in the present study complied with the guide for care and use of laboratory animals, and the experimental protocol was approved by the UNIFESP Ethical Committee (0876/09).

2.2. Paradoxical Sleep Deprivation/Sleep Restriction Procedure. Naïve rats were randomly distributed into three groups: paradoxical sleep deprivation (PSD), sleep restriction (SR), and home-cage controls (CTRL). The chronic partial SR group was subjected to SR for $18 \mathrm{~h}$ (beginning at $16: 00 \mathrm{~h}$ ) per day for 21 consecutive days (SR21 $n=10)$. After each $18 \mathrm{~h}$ sleep deprivation period, the rats were allowed to sleep for $6 \mathrm{~h}$ (sleep window beginning at 10:00). Throughout the SR procedure, rats slept an average of $30-40 \%$ of the time, corresponding to $8-9 \mathrm{~h}$ per day. This sleep interval (10:0016:00 h) was chosen because this is when paradoxical sleep attains its highest expression, and slow wave-sleep homeostatic pressure is generated [25-27].

The SD procedure consisted of placing rats in a container with a narrow cylindrical platform $6.5 \mathrm{~cm}$ in diameter surrounded by water about $1 \mathrm{~cm}$ below the platform surface. Each rat was placed individually in the container, and food and water were available ad libitum throughout the entire experimental period. At the onset of a paradoxical sleep episode, rats experienced loss of muscle tonus and fell into the water, thus being awakened.

2.3. Hormonal Assay. After the PSD/SR period, the rats were brought to an adjacent room and decapitated with minimum discomfort between 09:00 $\mathrm{h}$ and noon. The control group rats were euthanized at the same time as the experimental group and the other $50 \%$ were euthanized on the first day of the experimental procedure. Blood was collected in glass tubes and centrifuged to obtain samples of serum or plasma. The samples were maintained at $-20^{\circ} \mathrm{C}$ until assay. Each hormone assay of the samples from the five groups was analyzed on the same day. The intraassay coefficient variations are given in parentheses. Testosterone concentration (6.7\%) was measured by chemiluminescent immunometric assay (Immulite Automated Analyses; Diagnostic Products Corporation, Los Angeles, CA, USA), with a detection threshold of $10 \mathrm{ng} \mathrm{dL}{ }^{-1}$. Corticosterone (10.3\%) concentrations were assayed by a double-antibody RIA method specifically for rats and mice, using a commercial kit (ICN Biomedicals, Costa Mesa, CA, USA). The sensitivity of the assay is $0.25 \mathrm{ng} \mathrm{dL}^{-1}$.

2.4. Tissue Collection. For light microscopy, the ventral prostates were removed and immediately fixed by a $24 \mathrm{~h}$ immersion in Karnovsky fixative (0.1 M phosphate buffer, $\mathrm{pH}$ 7.2, containing $4 \%$ paraformaldehyde and $2.5 \%$ glutaraldehyde). Fixed tissues were dehydrated in a graded ethanol series and embedded in paraffin or glycol methacrylate resin (Historesin embedding kit, Leica, Heidelberg, Germany). Sections were cut at $3 \mu \mathrm{m}$ and stained with hematoxylin and eosin (H\&E) for general histological studies. Analyses were carried out using either a Zeiss Jenaval light microscope (Carl Zeiss, Jena, Germany) or an Olympus BX60 (Hamburg, Germany).

2.5. Morphometric and Stereological Analyses. Random prostatic fields from $\mathrm{H} \& \mathrm{E}$ sections were analyzed using the software Image-Pro-Plus version 4.5 for Windows (Media Cybernetic). Stereological analyses were carried out using Weibel's multipurpose graticulate with 130 points and 60 test lines [28], to compare the relative proportion (relative volume) of each prostatic tissue component (epithelium, lumen, and stroma), as described by Huttunen and collaborators (1981) and modified by Vilamaior and collaborators (2006) for prostatic tissue $[29,30]$. Thirty microscopic fields were chosen at random. In summary, the relative values were determined by counting the coincident points of the test grid and dividing them by the total number of points. The absolute volume of each of these compartments was determined by multiplying the relative volume value by the mean prostatic weight, based on the determination that $1 \mathrm{mg}$ of fresh rat ventral tissue had a volume of approximately $1 \mathrm{~mm}^{3}$ [30]. For the morphometrical analyses, 200 random measurements of epithelium height were also obtained.

2.6. Statistical Analysis. The quantitative results are expressed as means \pm standard errors. One-way ANOVA was followed by Tukey's test. The level of statistical significance was set at $P \leq 0.05$.

\section{Results}

3.1. Hormonal Levels. Plasma testosterone fell drastically in both groups. After $96 \mathrm{~h}$ PSD, testosterone was $87 \%$ lower than in the control group $(436.0 \pm 68.0$ versus $58.0 \pm$ $\left.8.2 \mathrm{ng} \mathrm{dL}^{-1} ; P<0.01\right)$. The 21 -day SR group's testosterone levels fell $65 \%$ in regarding control group $(436.0 \pm 68.0$ versus $152.7 \pm 22.2 \mathrm{ng} \mathrm{dL}^{-1} ; P<0.01$ ), as shown in Figure 1 .

Corticosterone values are shown in Figure 2. The ANOVA test showed the effect of the PSD and SR groups on corticosterone levels $[F(3.49)=13.92 ; P<0.001]$. Subsequent post hoc analysis revealed that corticosterone 


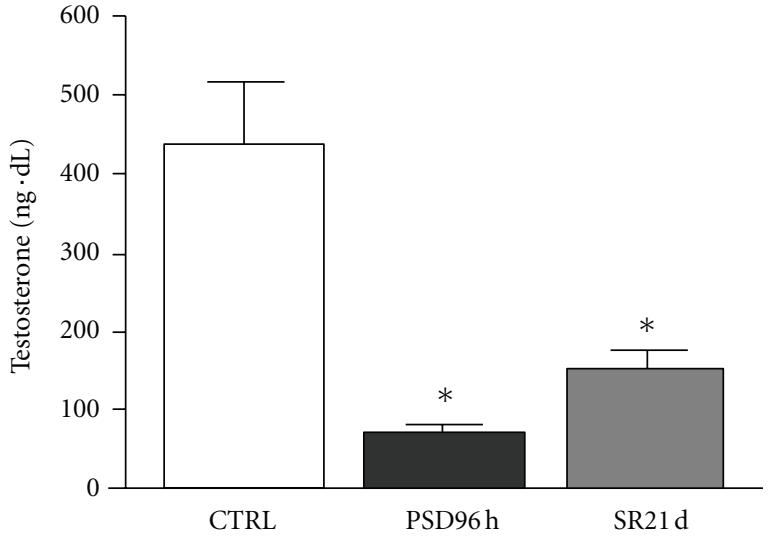

Figure 1: Mean \pm SD concentration of serum testosterone (in ng $\mathrm{dL}^{-1}$ ) control group (CTRL), paradoxal sleep deprivation (PSP) and sleep restriction $(\mathrm{SR})$ at different time points. ${ }^{*}$ Different from control group $(P<0.01)$.

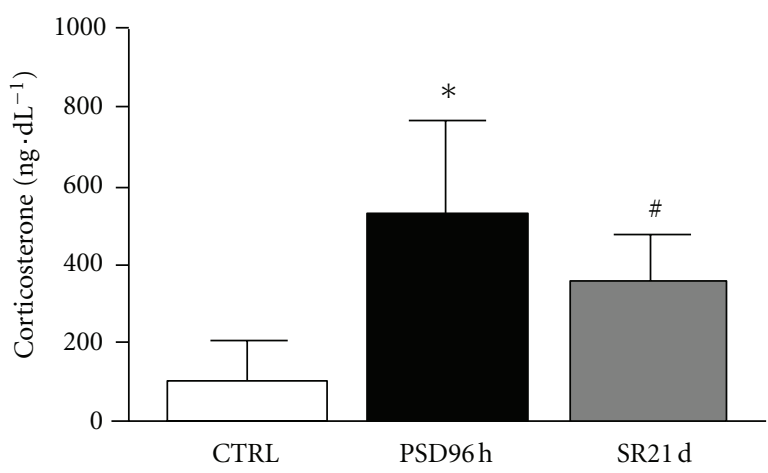

FIGURE 2: Mean \pm SD concentration of plasma corticosterone (in ng $\mathrm{dL}^{-1}$ ) of control group (CTRL), sleep deprivation (PSP), and sleep restriction $(\mathrm{SR})$ at different time points. ${ }^{*}$ Different from all groups $(P<0.01)$; ${ }^{\#}$ different from control group $(P<0.01)$.

concentrations after $96 \mathrm{~h}$ of PSD $(P<0.001)$ were higher than in the control 8 group and 21 days of SR. Furthermore, corticosterone levels after 21 days of SR were statistically different from the control group $(P<0.01)$.

3.2. Prostate Histology. Structural analysis of the ventral prostate using ordinary light microscopy demonstrated that the ventral prostate tissue was affected in the PSD 96-h and SR 21-day protocols. Figure 3 shows major alterations in prostatic tissue morphology, evidenced by epithelium alterations. Epithelial infoldings of apoptotic figures appeared and interestingly, there was an accumulation of fat cells in prostatic gland stroma, particularly in rats subjected to the SR procedure.

Morphometric and stereological evaluation of prostatic compartments (Table 1) showed regression of epithelium height in PSD96 and SR groups $(P<0.001)$ relative to the control group. The relative epithelial volume did not show any differences relative to the control groups. On the other hand, relative volumes of the stroma and lumen in the
TABLE 1

\begin{tabular}{lccc}
\hline & Control & PSD96h & SR21 \\
\hline $\begin{array}{l}\text { Morphometry } \\
\text { Epithelium height } \\
(\mu \mathrm{m})\end{array}$ & $43.42 \pm 7.3$ & $38.7 \pm 5.4^{*}$ & $38.5 \pm 5.2^{*}$ \\
\hline $\begin{array}{l}\text { Estereology } \\
\text { Epithelium }\end{array}$ & & & \\
$\quad$ RV (\%) & $33.84 \pm 2.33$ & $31.6 \pm 7.2$ & $29.1 \pm 7$ \\
AV (mg) & $35.43 \pm 2.44$ & $25.88 \pm 1.71^{*}$ & $22.52 \pm 1.08^{*}$ \\
Stroma & & & \\
RV (\%) & $10.7 \pm 0.67$ & $12.2 \pm 6^{*}$ & $20.2 \pm 8.7^{* \#}$ \\
AV (mg) & $11.17 \pm 0.67$ & $10.02 \pm 0.97$ & $15.65 \pm 1.35^{* \#}$ \\
Lumen & & & \\
RV (\%) & $55.5 \pm 13.3$ & $56.2 \pm 10$ & $50.8 \pm 9^{* \#}$ \\
AV (mg) & $58.07 \pm 2.79$ & $45.99 \pm 1.63^{*}$ & $39.36 \pm 1.40^{*}$ \\
\hline
\end{tabular}

Values represent means \pm SEMs of the data obtained for stereological and morphometrical analyses of three experimental groups: control, PSD96 h and SR21. Statistical analyses based on ANOVA and Tukey tests. Significance $P<0.05$. ${ }^{*}$ Different from control group and different from PSD96h. RV: relative volume. AV: absolute volume.

SR group were significantly different from the control and PSD96 volumes $(P<0.001)$. However, the absolute volume of the lumen in the SR group declined relative to both the control and PSD96 rats $(P<0.001)$.

\section{Discussion}

The purpose of this study was to evaluate the effects of 96hour SD and 21-day SR on prostate morphology in rats. The main findings were that prostate tissue responded to $96 \mathrm{~h}$ PSD with the presence of apoptotic bodies and diminished epithelium height, which indicates regression of the prostatic secretion function (glandular atrophy). The SR group showed diminished epithelium and lumen height. In addition, fat cells were observed in the stroma in the SR group. Both sleep-deprivation procedures caused higher corticosterone and lower testosterone levels.

Our data confirm previous findings about how sleep deprivation affects testosterone and corticosterone concentrations $[9,10,31,32]$. The abrupt fall in testosterone levels may be influenced by an elevation of hormones involved in the hypothalamic-pituitary-adrenal (HPA) axis, such as corticosterone. Therefore, it seems that glucocorticoids have the ability to suppress endocrine signaling in the reproductive axis $[9,10,31,33]$. In vitro studies show that Leydig cells are negatively regulated by the administration of corticosteroids [34]. Indeed, glucocorticoids directly inhibit transcription of genes responsible for the enzymatic mechanism that activates testosterone synthesis. Hales and Payne [34] reported that after treating Leydig cells with glucocorticoid in vitro, the gene transcription and subsequent synthesis of the protein responsible for cholesterol cleavage (which produces testosterone) was also inhibited. 
Control group
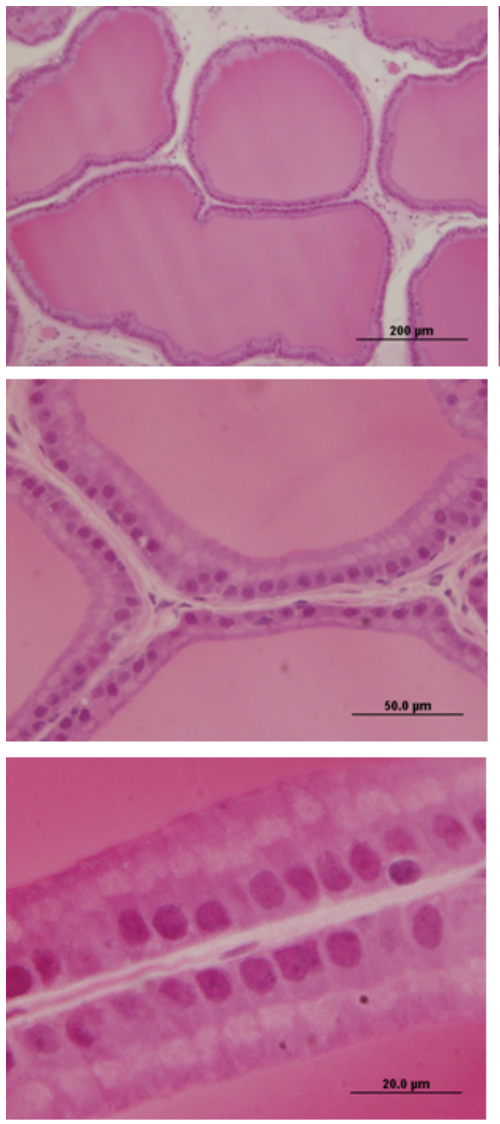

Sleep deprivation
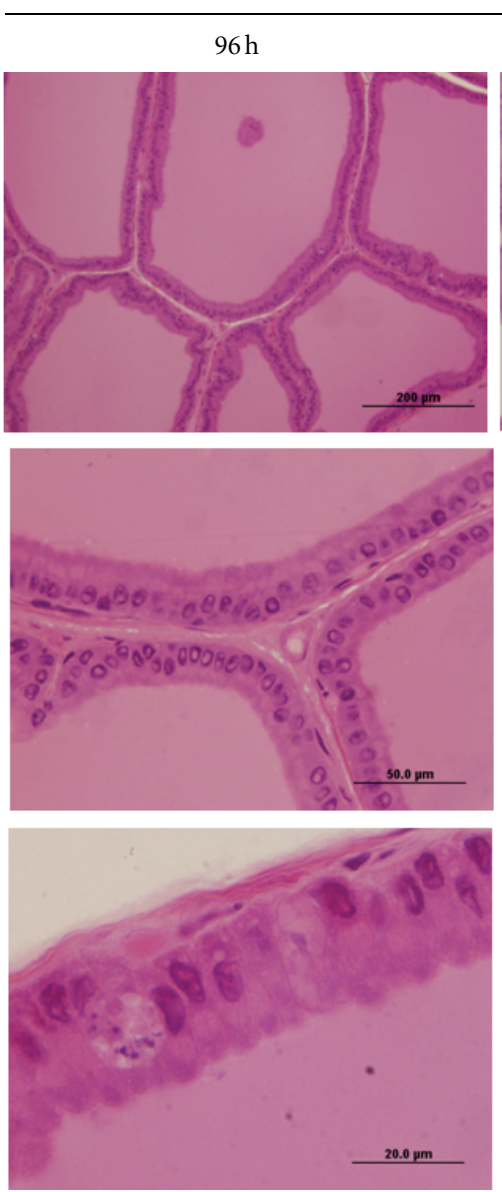
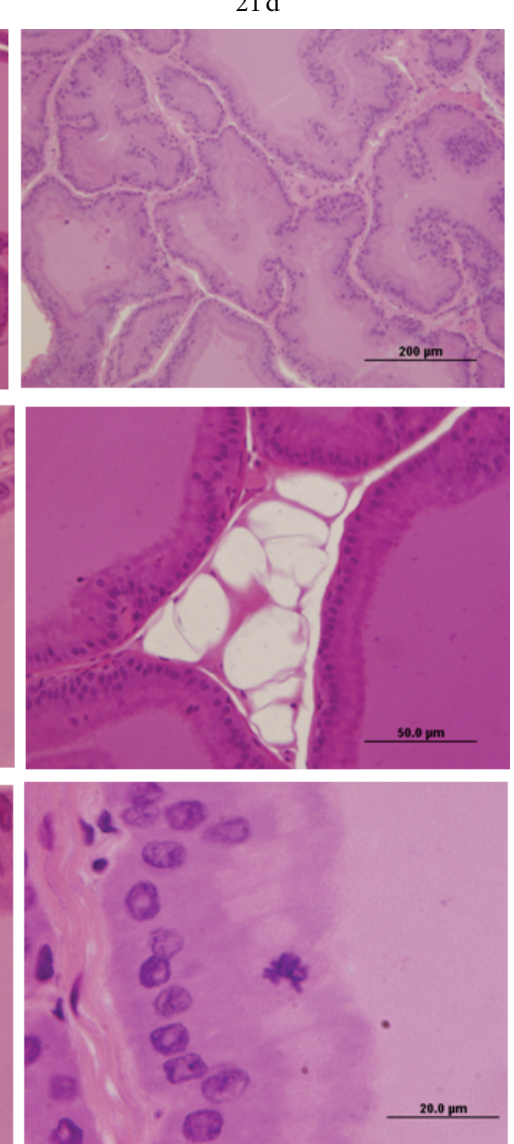

FIGURE 3: Haematoxylin and eosin stained histological sections of rat ventral prostatic tissue under different conditions of sleep deprivation. The prostate of control group shows the acini (Ac) with great amount of secretion in the luminal region (Lu), and the epithelium (Ep) is visualized with conspicuous Golgi's region (star), indicative of high secretion activity. During the sleep deprivation conditions, the acini compartment is decreased, and the presence of unilocular adipose tissue is evident $\left(^{*}\right)$. The thin arrow indicates an apoptotic body in the epithelium. Stroma (S).

High glucocorticoid concentrations downmodulate the reproductive axis at the hypothalamus and pituitary levels, showing that they have deleterious effects on the expression of gonadotrophin-releasing hormone $(G n R H)$ mRNA and reduce LH plasma concentrations [35]. As shown by Andersen and coworkers, plasma testosterone reduction during sleep deprivation is directly related to higher corticosterone levels $[11,12]$.

Testosterone is a critical hormone for prostate development, growth, and maintenance [30]. Prostatic morphogenesis is determined not genetically, but by exposure to androgens produced by the testes in the fetus $[36,37]$. Therefore, insensitivity to androgens hinders prostate development. It has been shown that androgen stimulation at the correct time during embryogenesis can modulate prostate tissue growth in both males and females [38]. Several studies have shown that the prostate undergoes more marked alterations in epithelial and stromal compartments after hormonal and surgical ablation. These procedures lead to a decrease in glandular function, with consequent declines in epithelium thickness and stromal volume $[39,40]$. In the current study, we found diminished epithelium height in rats subjected to PSD $96 \mathrm{~h}$ and SR. Androgen levels are clearly lowered during sleep deprivation [9-12, 41]. Maintenance of prostate physiology depends on circulating androgens and more specifically on dihydrotestosterone levels $[42,43]$. Therefore, this hormone seems to be more potent than testosterone in stimulating epithelium growth and maintenance, although they have the same ability to prevent cell death after castration [44]. Androgens play a central role in regulating growth and maintenance of the active functional state of the prostate gland in mammals and can stimulate and inhibit the death of epithelial glandular cells $[24,45]$. There is strong evidence that the low levels of circulating androgens seen in the PSD96 group may have started the apoptotic process in the rat ventral prostate, which led to diminished volume and thus glandular atrophy and decreased function.

Ribeiro and collaborators (2008) showed that dexamethasone treatment in male rats induced atrophy and reduced the proliferative capacity of epithelial cells. The same 
treatment also led to altered epithelium-stroma interactions. Smooth muscle cells showed an atrophic contractile pattern and high electron density of the mitochondrial matrix [46]. The high concentration of circulating corticosterone may have led to the reduced epithelium height in the experimental groups studied here. In addition, accumulation of fat cells in the stroma was observed in the group of rats subjected to SR21. We do not know what impact reduced circulating levels of androgens has in this phenomenon, since we found that animals castrated after 21 days did not present this phenomenon; it is not even known whether this may be related to high levels of corticosterone or some other hormone [47].

Taken as a whole, our results suggest that both paradoxical sleep deprivation and sleep restriction strongly influence the ventral prostate alterations observed in this study. These observed morphological alterations could be induced by two mechanisms mediated by SD and/or SR: the drastic reduction in testosterone levels (important for organ morphology maintenance) or the increase in corticosterone levels, which can act directly on the cytoplasmic receptors of the prostate cells.

\section{Conflict of Interests}

The authors declare that they have no conflict of interests associated with this paper.

\section{Acknowledgments}

This paper is part of the thesis presented by D. P. Venâncio to the Department of Nutrition of the Universidade Federal de São Paulo (UNIFESP-EPM), in partial fulfillment of the requirement for a doctoral degree in science. The authors wish to thank to Mr. Luiz Roberto Falleiros Júnior for technical assistance. This work was supported by National Council of Scientific and Technological Development (CNPq): Research Fellowships to M. L. Andersen, S. R. Taboga, S. Tufik, M. T. De Mello.

\section{References}

[1] S. M. Rajaratnam and J. Arendt, "Health in a 24-h society," The Lancet, vol. 358, no. 9286, pp. 999-1005, 2001.

[2] C. A. Everson, "Sustained sleep deprivation impairs host defense," American Journal of Physiology, vol. 265, no. 5, pp. R1148-R1154, 1993.

[3] B. D. Palma, A. Gabriel Jr., F. A. B. Colugnati, and S. Tufik, "Effects of sleep deprivation on the development of autoimmune disease in an experimental model of systemic lupus erythematosus," American Journal of Physiology, vol. 291, no. 5, pp. R1527-R1532, 2006.

[4] F. S. Ruiz, M. L. Andersen, A. Zager, R. C. S. Martins, and S. Tufik, "Sleep deprivation reduces the lymphocyte count in a non-obese mouse model of type 1 diabetes mellitus," Brazilian Journal of Medical and Biological Research, vol. 40, no. 5, pp. 633-637, 2007.

[5] A. Zager, M. L. Andersen, F. S. Ruiz, I. B. Antunes, and S. Tufik, "Effects of acute and chronic sleep loss on immune modulation of rats," American Journal of Physiology, vol. 293, no. 1, pp. R504-R509, 2007.

[6] T. A. Alvarenga, C. L. Patti, M. L. Andersen et al., "Paradoxical sleep deprivation impairs acquisition, consolidation, and retrieval of a discriminative avoidance task in rats," Neurobiology of Learning and Memory, vol. 90, no. 4, pp. 624-632, 2008.

[7] R. H. Silva, V. C. Abílio, A. L. Takatsu et al., "Role of hippocampal oxidative stress in memory deficits induced by sleep deprivation in mice," Neuropharmacology, vol. 46, no. 6, pp. 895-903, 2004.

[8] J. L. Tartar, C. P. Ward, J. T. McKenna et al., "Hippocampal synaptic plasticity and spatial learning are impaired in a rat model of sleep fragmentation," European Journal of Neuroscience, vol. 23, no. 10, pp. 2739-2748, 2006.

[9] M. L. Andersen, M. Bignotto, R. B. Machado, and S. Tufik, "Different stress modalities result in distinct steroid hormone responses by male rats," Brazilian Journal of Medical and Biological Research, vol. 37, no. 6, pp. 791-797, 2004.

[10] M. L. Andersen, L. A. Papale, and S. Tufik, "Diurnal variation in the genital reflexes and hormone levels induced by paradoxical sleep deprivation and cocaine in male rats," Brain Research Bulletin, vol. 64, no. 3, pp. 215-220, 2004.

[11] M. L. Andersen, V. D’Almeida, P. J. F. Martins, H. K. M. Antunes, and S. Tufik, "Effects of paradoxical sleep deprivation and cocaine on genital reflexes in hyperlipidic-fed rats," Pharmacology Biochemistry and Behavior, vol. 81, no. 4, pp. 758-763, 2005.

[12] M. L. Andersen, P. J. F. Martins, V. D’Almeida, M. Bignotto, and S. Tufik, "Endocrinological and catecholaminergic alterations during sleep deprivation and recovery in male rats," Journal of Sleep Research, vol. 14, no. 1, pp. 83-90, 2005.

[13] E. Y. Kim, G. S. Mahmoud, and L. M. Grover, "REM sleep deprivation inhibits LTP in vivo in area CA1 of rat hippocampus," Neuroscience Letters, vol. 388, no. 3, pp. 163-167, 2005.

[14] C. Mirescu, J. D. Peters, L. Noiman, and E. Gould, "Sleep deprivation inhibits adult neurogenesis in the hippocampus by elevating glucocorticoids," Proceedings of the National Academy of Sciences of the United States of America, vol. 103, no. 50, pp. 19170-19175, 2006.

[15] R. Wolk and V. K. Somers, "Sleep and the metabolic syndrome," Experimental Physiology, vol. 92, no. 1, pp. 67-78, 2007.

[16] F. Singer and B. Zumoff, "Subnormal serum testosterone levels in male internal medicine residents," Steroids, vol. 57, no. 2, pp. 86-89, 1992.

[17] R. Luboshitzky, L. Lavie, Z. Shen-Orr, and P. Herer, "Altered luteinizing hormone and testosterone secretion in middleaged obese men with obstructive sleep apnea," Obesity Research, vol. 13, no. 4, pp. 780-786, 2005.

[18] M. A. Gonçalves, C. Guilleminault, E. Ramos, A. Palha, and T. Paiva, "Erectile dysfunction, obstructive sleep apnea syndrome and nasal CPAP treatment," Sleep Medicine, vol. 6, no. 4, pp. 333-339, 2005.

[19] D. Margel, M. Cohen, P. M. Livne, and G. Pillar, "Severe, but not mild, obstructive sleep apnea syndrome is associated with erectile dysfunction," Urology, vol. 63, no. 3, pp. 545-549, 2004.

[20] M. L. Andersen, J. C. Perry, M. C. Battisti et al., "Association of paradoxical sleep deprivation and ecstasy (MDMA) enhances genital reflexes in male rats," Behavioural Brain Research, vol. 170, no. 2, pp. 287-292, 2006.

[21] M. L. Andersen, J. C. Perry, I. B. Antunes, and S. Tufik, "Involvement of nitric oxide in cocaine-induced erections and ejaculations after paradoxical sleep deprivation," Progress in 
Neuro-Psychopharmacology and Biological Psychiatry, vol. 31, no. 3, pp. 652-657, 2007.

[22] S. Mathur and P. P. Chattopadhyay, "Effect of sleep deprivation on the physiological status of rat testis," Andrologia, vol. 23, no. 1, pp. 49-51, 1991.

[23] R. Demura, T. Suzuki, S. Nakamura, H. Komatsu, E. Odagiri, and H. Demura, "Effect of immobilization stress on testosterone and inhibin in male rats," Journal of Andrology, vol. 10, no. 3, pp. 210-213, 1989.

[24] N. Kyprianou and J. T. Isaacs, "Activation of programmed cell death in the rat ventral prostate after castration," Endocrinology, vol. 122, no. 2, pp. 552-562, 1988.

[25] P. Franken, I. Tobler, and A. A. Borbely, "Sleep homeostasis in the rat: simulation of the time course of EEG slow-wave activity," Neuroscience Letters, vol. 130, no. 2, pp. 141-144, 1991.

[26] R. B. Machado, D. C. Hipólide, A. A. Benedito-Silva, and S. Tufik, "Sleep deprivation induced by the modified multiple platform technique: quantification of sleep loss and recovery," Brain Research, vol. 1004, no. 1-2, pp. 45-51, 2004.

[27] C. Timo-Iaria, N. Negrào, W. R. Schmidek, K. Hoshino, C. E. L. de Menezes, and T. L. da Rocha, "Phases and states of sleep in the rat," Physiology and Behavior, vol. 5, no. 9, pp. 10571062, 1970.

[28] E. R. WEIBEL, "Principles and methods for the morphometric study of the lung and other organs," Laboratory Investigation, vol. 12, pp. 131-155, 1963.

[29] E. Huttunen, T. Romppanen, and H. J. Helminen, "A histoquantitative study on the effects of castration on the rat ventral prostate lobe," Journal of Anatomy, vol. 132, no. 3, pp. 357-370, 1981.

[30] P. S. L. Vilamaior, S. R. Taboga, and H. F. Carvalho, "Postnatal growth of the ventral prostate in Wistar rats: a stereological and morphometrical study," Anatomical Record A, vol. 288, no. 8, pp. 885-892, 2006.

[31] D. C. Hipólide, D. Suchecki, A. P. de Carvalho Pinto, E. Chiconelli Faria, S. Tufik, and J. Luz, "Paradoxical sleep deprivation and sleep recovery: effects on the hypothalamic-pituitaryadrenal axis activity, energy balance and body composition of rats," Journal of Neuroendocrinology, vol. 18, no. 4, pp. 231238, 2006.

[32] A. Sgoifo, B. Buwalda, M. Roos, T. Costoli, G. Merati, and P. Meerlo, "Effects of sleep deprivation on cardiac autonomic and pituitary- adrenocortical stress reactivity in rats," Psychoneuroendocrinology, vol. 31, no. 2, pp. 197-208, 2006.

[33] T. E. Orr and D. R. Mann, "Role of glucocorticoids in the stress-induced suppression of testicular steroidogenesis in adult male rats," Hormones and Behavior, vol. 26, no. 3, pp. 350-363, 1992.

[34] D. B. Hales and A. H. Payne, "Glucocorticoid-mediated repression of P450(SCC) mRNA and de novo synthesis in cultured Leydig cells," Endocrinology, vol. 124, no. 5, pp. 2099 2104, 1989.

[35] A. C. Gore, B. Attardi, and D. B. DeFranco, "Glucocorticoid repression of the reproductive axis: effects on $\mathrm{GnRH}$ and gonadotropin subunit mRNA levels," Molecular and Cellular Endocrinology, vol. 256, no. 1-2, pp. 40-48, 2006.

[36] G. R. Cunha, A. A. Donjacour, P. S. Cooke et al., "The endocrinology and developmental biology of the prostate," Endocrine Reviews, vol. 8, no. 3, pp. 338-362, 1987.

[37] G. Pointis, M. T. Latreille, and L. Cedard, "Gonado-pituitary relationships in the fetal mouse at various times during sexual differentiation," Journal of Endocrinology, vol. 86, no. 3, pp. 483-488, 1980.
[38] H. Takeda, I. Lasnitzki, and T. Mizuno, "Analysis of prostatic bud induction by brief androgen treatment in the fetal rat urogenital sinus," Journal of Endocrinology, vol. 110, no. 3, pp. 467-470, 1986.

[39] R. S. Cordeiro, W. R. Scarano, R. M. Góes, and S. R. Taboga, "Tissue alterations in the Guinea pig lateral prostate following antiandrogen flutamide therapy," Biocell, vol. 28, no. 1, pp. 21$30,2004$.

[40] L. S. Corradi, R. M. Gòes, H. F. Carvalho, and S. R. Taboga, "Inhibition of 5- $\alpha$-reductase activity induces stromal remodeling and smooth muscle de-differentiation in adult gerbil ventral prostate," Differentiation, vol. 72, no. 5, pp. 198-208, 2004.

[41] M. R. Gonzalez-Santos, O. V. Gaja-Rodriguez, R. AlonsoUriarte, I. Sojo-Aranda, and V. Cortes-Gallegos, "Sleep deprivation and adaptive hormonal responses of healthy men," Archives of Andrology, vol. 22, no. 3, pp. 203-207, 1989.

[42] J. Imperato-McGinley, R. S. Sanchez, J. R. Spencer, B. Yee, and E. D. Vaughan, "Comparison of the effects of the $5 \alpha$-reductase inhibitor finasteride and the antiandrogen flutamide on prostate and genital differentiation: dose- response studies," Endocrinology, vol. 131, no. 3, pp. 1149-1156, 1992.

[43] J. D. Wilson, J. E. Griffin, and D. W. Russell, "Steroid $5 \alpha$ reductase 2 deficiency," Endocrine Reviews, vol. 14, no. 5, pp. 577-593, 1993.

[44] A. S. Wright, L. N. Thomas, R. C. Douglas, C. B. Lazier, and R. S. Rittmaster, "Relative potency of testosterone and dihydrotestosterone in preventing atrophy and apoptosis in the prostate of the castrated rat," Journal of Clinical Investigation, vol. 98, no. 11, pp. 2558-2563, 1996.

[45] J. T. Isaacs, "Antagonistic effect of androgen on prostatic cell death," Prostate, vol. 5, no. 5, pp. 545-557, 1984.

[46] D. L. Ribeiro, A. Rafacho, J. R. Bosqueiro, S. R. Taboga, and R. M. Góes, "Cellular changes in the prostatic stroma of glucocorticoid-treated rats," Cell and Tissue Research, vol. 332, no. 3, pp. 499-508, 2008.

[47] P. S. L. Vilamaior, S. R. Taboga, and H. F. Carvalho, "Modulation of smooth muscle cell function: morphological evidence for a contractile to synthetic transition in the rat ventral prostate after castration," Cell Biology International, vol. 29, no. 9, pp. 809-816, 2005. 


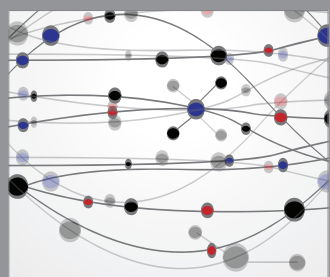

The Scientific World Journal
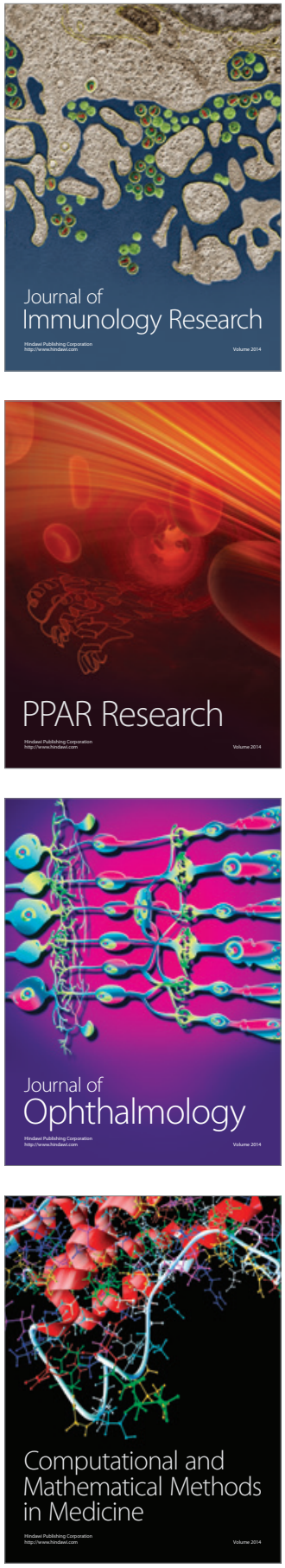

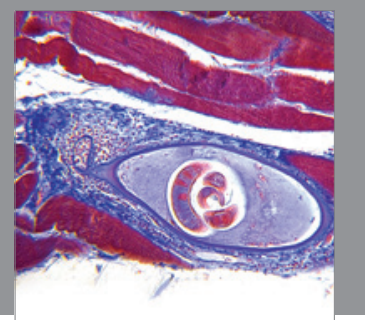

Gastroenterology

Research and Practice
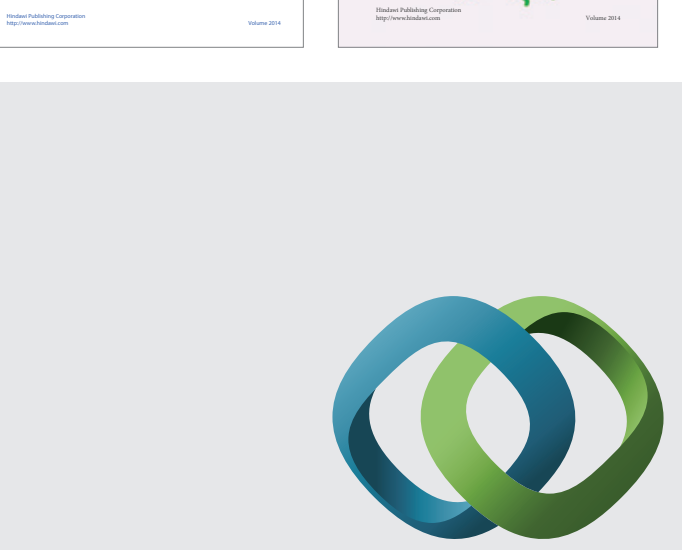

\section{Hindawi}

Submit your manuscripts at

http://www.hindawi.com
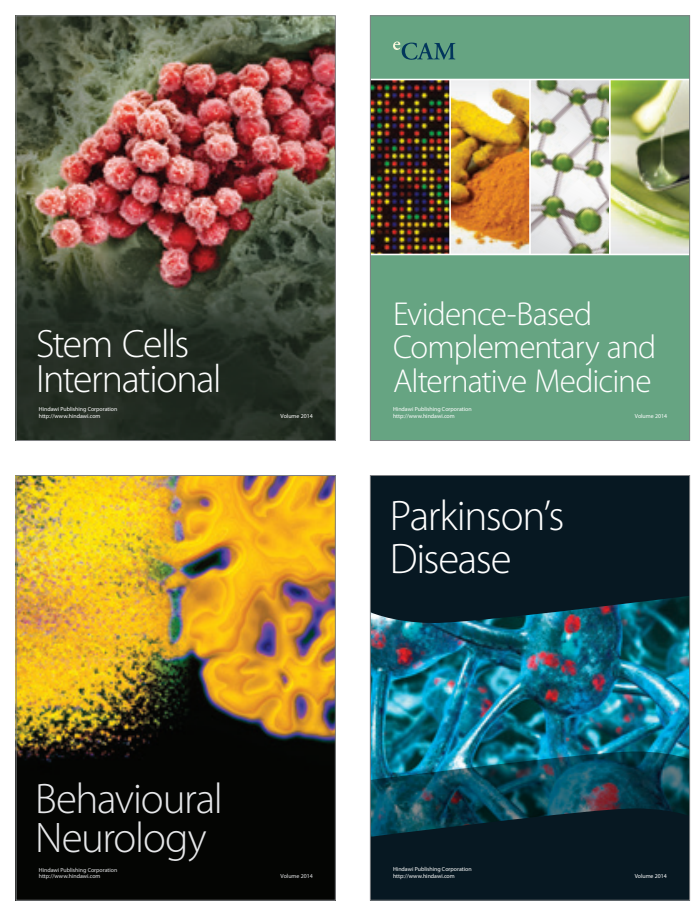

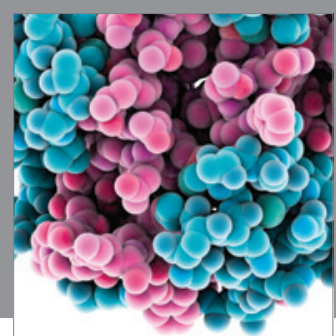

Journal of
Diabetes Research

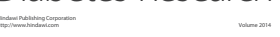

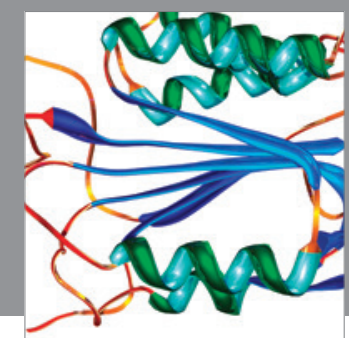

Disease Markers
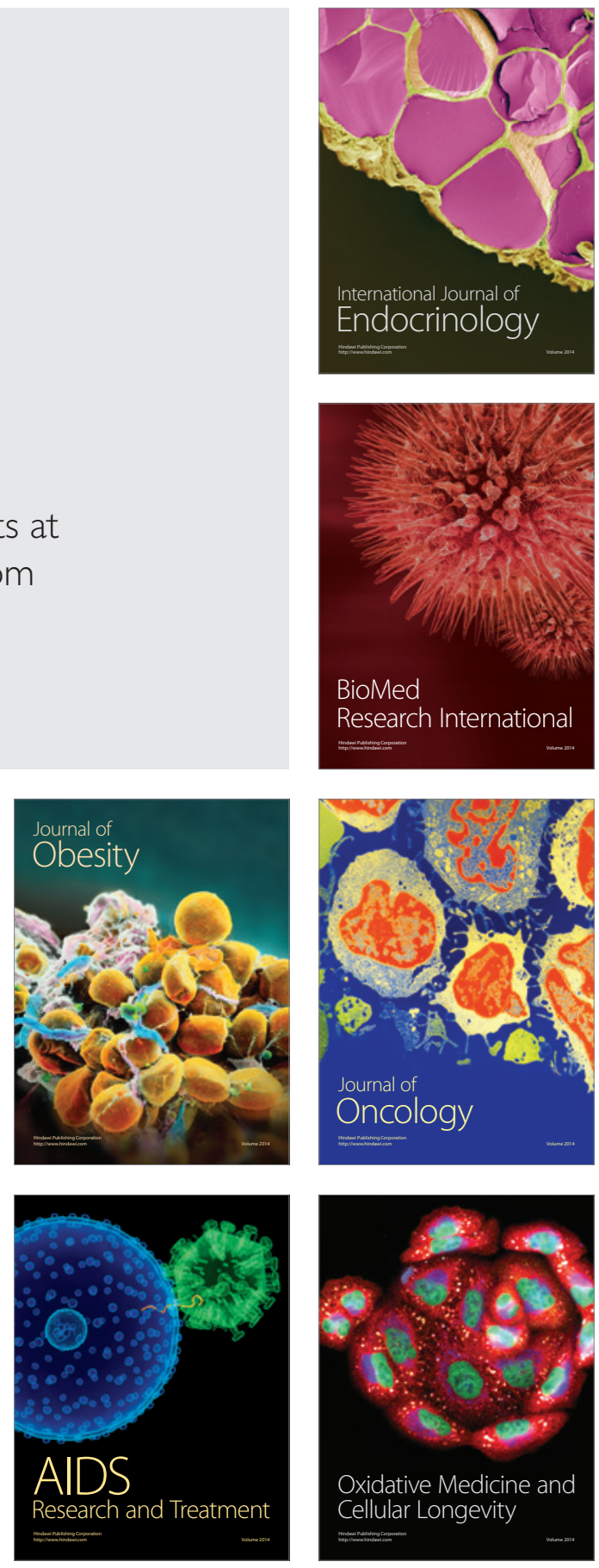